\title{
CONTABILIDADE: AS PRIMEIRAS PERCEPÇÕES RELACIONADAS À CRISE DE COVID-19
}

\author{
Beatriz Pereira Ferreira Alves \\ Altamiro Lacerda de Almeida Junior \\ Jaqueline Aparecida Bayonetta de Souza \\ Silene Aparecida Zampier Alves \\ Patrícia Margato da Silva Rodrigues
}

\section{RESUMO}

Este estudo discorre sobre as primeiras percepções relacionadas à crise de COVID-19 no âmbito da contabilidade. Tal abordagem é devida ao fato de que houve muitas mudanças e atualização na legislação brasileira para incorporação de medidas tributarias e de manutenção de empregos a fim de evitar demissões em massa e ajudar as empresas a se manterem nesse período de crise, o que acarreta uma fase de grande adaptação e um aumento de demanda de trabalho para os empresários e especificamente os escritórios de contabilidade. A finalidade deste estudo é demonstrar como tem sido as primeiras medidas de enfrentamento dos contadores e contabilistas diante de tal cenário. Este estudo possui uma natureza qualitativa e exploratória. O estudo evidenciou que não houve muitas demissões no setor de contabilidade, o que pode estar relacionado ao aumento dos serviços ocasionados por outras demissões que precisaram ser realizadas pelos profissionais de contabilidade, assim como o aumento dos estudos e repasse de informações aos clientes, para adequação às leis e normas implementadas pelo Governo nesse período de pandemia. $O$ estudo demonstrou também que a maioria dos entrevistados não estão organizados, confortáveis, motivados para o trabalho em home office, uma vez que este tipo de trabalho afeta no desempenho das tarefas e a grande maioria dos entrevistados preferem a modalidade presencial.

Palavras chave: Contabilidade, Contadores, Covid-19

\section{INTRODUÇÃO}

Atualmente vivemos uma situação sem nenhum precedente, e o ano de 2020 começou com um grande desafio para os empresários brasileiros, entre eles os escritórios de contabilidade. A crise que vem impactando o mundo inteiro, tanto na saúde quanto na economia, está obrigando os empreendedores a repensarem seus métodos de trabalho. Cada dia que passa, os empresários reavaliam as medidas que podem tomar diante da crise causada pela COVID-19 (MARQUES,2020).

Neste cenário o contador tem um papel fundamental, por isso, agora, mais do que nunca, os contadores devem se informar e estudar sobre todos os cenários e medidas impostas pelo governo (CORREA, 2020), para auxiliar e apresentar todas as medidas aos seus clientes e garantir que adotem as melhores condutas para manter a sustentabilidade dos negócios durante a pandemia do coronavírus. 
A finalidade deste estudo é demonstrar como tem sido as primeiras medidas de enfrentamento dos contadores e contabilistas diante de tal cenário. Este estudo possui uma natureza qualitativa e exploratória, constitui um estudo de caso do tipo descritivo, em que empregou-se como instrumentos de pesquisa, a revisão bibliográfica em periódicos, livros e sites, e entrevista com uso de formulários on-line. Obteve-se quarenta e duas respostas aos formulários enviados para escritórios de contabilidade e contabilistas de CataguasesMG. A pesquisa se deu entre os meses de maio e junho de 2020. Utilizou-se para análise dos dados a técnica de análise de conteúdo.

\section{A CONTABILIDADE, O PROFISSIONAL DE CONTABILIDADE E OS SERVIÇOS}

Segundo Hendriksen e Van Breda (1999), não se sabe quem inventou a contabilidade, o que se sabe é que existem registros de transações financeiras de quatro mil anos atrás, e que foi na Itália em meados do século XIV que surgiu o sistema de escrituração por partidas dobradas que se utiliza atualmente.

O senso-comum geralmente associa a contabilidade a uma ciência exata, entretanto, cientificamente a Contabilidade é enquadrada no campo das ciências sociais aplicadas (IUDÍCIBUS, 2010).

A Contabilidade se adapta as transformações e desenvolvimento da sociedade, ainda de acordo com Hendriksen \& Breda (1999, p.38) a Contabilidade desenvolveu-se em resposta a mudanças no ambiente, novas descobertas e progressos tecnológicos. Não há motivo para crer que a Contabilidade não continue a evoluir em resposta a mudanças que estamos observando em nossos tempos.

O profissional contábil deve sempre buscar as oportunidades de atualização de seus conhecimentos, seja devido ao dinamismo do mercado, seja devido às frequentes modificações efetuadas nas normas contábeis e na legislação (VIELLE, BIANCHI, 2016). A Contabilidade necessita sempre se sintonizar com a evolução social e tecnológica (SANTOS et al., 2008).

Os escritórios contábeis são sociedades civis, constituídas com o objetivo de prestar serviços contábeis para outras organizações industriais, comerciais e outras prestadoras de serviços. A Resolução CFC n. 1.098/07 discrimina duas modalidades de organizações contábeis: escritório individual, caracterizado quando o contabilista, embora sem personificação jurídica, executa suas atividades independentemente do local e do número de empresas ou serviços sob sua responsabilidade; e organização contábil, que se trata de pessoa jurídica de natureza civil, constituída sob a forma de sociedade, tendo por objetivo a prestação de serviços profissionais de contabilidade. (WRUBEL, TOIGO E LAVARDA, 2015)

Thomé (2001) aborda que os serviços prestados são: a escrituração contábil, a conciliação de contas, a elaboração de demonstrações financeiras, as declarações fiscais, a contabilidade gerencial, as obrigações acessórias e eletrônicas, entre outros.

Para cumprir com todos os prazos e todas essas obrigações os escritórios buscam se organizar em rotinas sistemáticas a fim de atender as necessidades dos clientes e as necessidades governamentais. (WRUBEL, TOIGO E LAVARDA, 2015) 


\section{COVID-19 NO BRASIL E NO MUNDO}

A Organização Mundial da Saúde (OMS) declarou, em 30 de janeiro de 2020, que o surto da doença causada pelo novo coronavírus (COVID-19) constitui uma Emergência de Saúde Pública de Importância Internacional - o mais alto nível de alerta da Organização, conforme previsto no Regulamento Sanitário Internacional. Em 11 de março de 2020, a COVID-19 foi caracterizada pela OMS como uma pandemia. (OPAS, 2020).

Os casos de Covid-19 confirmados no mundo, até 31 de maio de 2020 superaram os 6 milhões, conforme estudo levantado pelo monitoramento da universidade americana Johns Hopkins. Os EUA são o país com mais casos: cerca de 1,8 milhões. Em segundo lugar vem o Brasil, com 501.985 casos da doença. A Rússia é o terceiro país com mais infecções, com quase 500 mil casos. (G1, 2020).

A Covid-19 tem se difundido pelo mundo rapidamente e gerado choques econômicos com ritmo e intensidade acima dos observado na crise de 2008 e na grande depressão dos anos de 1930. (JUNIOR, RITA, 2020). Como chama atenção Nouriel Roubini (2020, p. 1) em artigo publicado no Project Syndicate,

[...] nesses dois episódios anteriores, os mercados de ações caíram $50 \%$ ou mais, os mercados de crédito congelaram, as falências em massa seguiram- se, as taxas de desemprego subiram acima de $10 \%$, e o PIB contraiu a uma taxa anualizada de $10 \%$ ou mais. Mas tudo isso levou cerca de três anos para acontecer. Na crise atual, resultados macroeconômicos e financeiros igualmente terríveis se materializaram em três semanas.

O Indicador Antecedente Composto da Economia Brasileira (Iace), calculado pelo Instituto Brasileiro de Economia, da Fundação Getúlio Vargas (FGV/Ibre), em parceria com o The Conference Board (TCB), caiu 10,1\% em abril de 2020, na comparação com março de 2020, passando de 112,6 para 101,2 pontos. (GANDRA, A., 2020).

É a maior queda da série histórica iniciada em 1996, de acordo com a FGV. Em março de 2020, o Iace teve redução de 6,2\% em relação a fevereiro de 2020 (120,1 pontos). Ele já mostra impactos da covid-19 na economia. (GANDRA, A., 2020).

Os autores JUNIOR, RITA (2020, p. 466,467), consideram que:

O efeito simultâneo da crise sobre a demanda e a oferta das economias pode se transformar em uma combinação bastante lesiva para economia, como pode ser observado no Figura 1. Em outras palavras, os reflexos das falências das empresas e do desemprego gerados no setor de serviços contaminarão a demanda por bens produzidos nos setores industrial e agrícola, que passarão a produzir menos aumentando o risco de desabastecimento. A consequência direta de tal dinâmica é o aumento da inadimplência das empresas e famílias causando uma crise financeira e o colapso do sistema de crédito. 
As políticas públicas terão que evitar tanto a paralisia do sistema de saúde, como os efeitos negativos do lockdown sobre as famílias, empresas e bancos. (JUNIOR, RITA, 2020).

Figura 1 - Dinâmica econômica do vírus sem políticas macroeconômicas compensatórias.

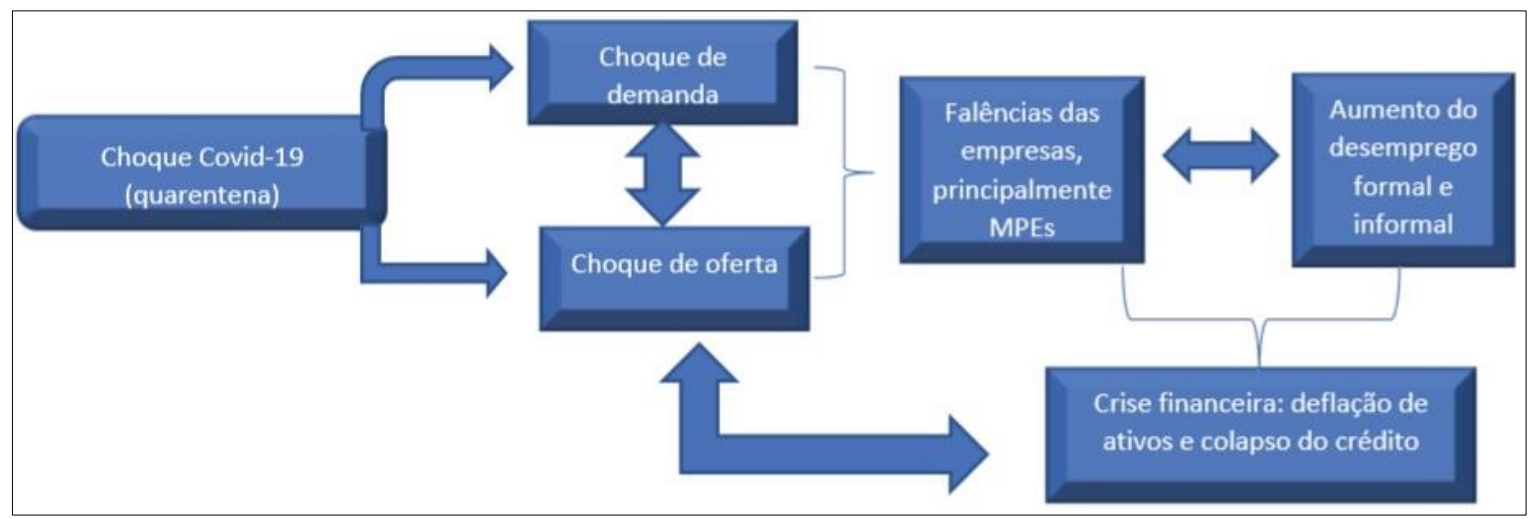

Fonte: (JUNIOR, RITA, 2020).

\section{ESTUDO DE CASO}

Após análise dos dados verificou-se que apenas 21,4\% dos entrevistados alteraram sua modalidade de trabalho, adotando o trabalho em home Office, os demais 78,6\% continuam na modalidade de trabalho presencial em escritórios e empresas.

Aproximadamente $75 \%$ dos entrevistados que disseram estar atuando em home office, afirmam que tem preferência pela modalidade de trabalho presencial.

Quando questionados sobre a estrutura do home office, $44 \%$ dos participantes acreditam que a estrutura que possuem (internet, computador e espaço) são boas, fato que contribui para os resultados do trabalho. Os demais $56 \%$ acreditam que a estrutura que possuem é regular.

Acerca do desempenho do trabalho nessa modalidade $22 \%$ dizem que está impactando nos prazos e na eficácia, enquanto $78 \%$ acreditam que atuar nessa modalidade não interfere na performance de seus resultados.

Verificou-se que a qualidade da estrutura do home Office pode afetar na produtividade do trabalho dos contadores, uma vez que os $22 \%$ que disseram que o trabalho remoto está impactando nos prazos e na eficácia, possuem uma estrutura regular para executarem suas tarefas.

A grande maioria dos entrevistados, aproximadamente 98\%, disseram manter sua rotina de horários, independente de estarem em trabalho home office ou no escritório. Os turnos de trabalho predominantes são manhã e tarde.

Em relação à cobrança da chefia imediata na modalidade de trabalho remoto $44 \%$ responderam que estão sendo mais cobrados e para $56 \%$ as exigências da chefia está normal. Já no trabalho presencial 36\% estão sendo mais cobrados e para $64 \%$ o nível de cobrança se manteve normal.

Averiguou-se a respeito das demissões no setor de contabilidade, para a maioria dos participantes, cerca de $74 \%$, afirmam que não perceberam muitas demissões neste setor. Porém quando questionados sobre demissões em outros setores da economia, aproximadamente $88 \%$ afirmam que houve mais demissões nesse período. 
Procurou-se investigar também sobre as obrigações acessórias e cerca de $90 \%$ dos entrevistados disseram não existir a redução dessas obrigações. Aproximadamente $88 \%$ dos participantes relataram que as medidas tributárias e medidas para manutenção de empregos, implementadas pelo Governo Federal, impactaram no aumento do trabalho dos contadores, devido, principalmente, aos estudos necessários para adequar à nova legislação.

\section{CONSIDERAÇÕES FINAIS}

O presente estudo nos permite inferir sobre a importância dos profissionais de contabilidade, principalmente nesse período de pandemia. Verificou-se que o trabalho ficou mais complexo, devido as atualizações e mudanças de leis, que precisaram ser compreendidas para serem aplicadas não apenas nos processos internos dos escritórios contábeis, mas para serem informadas aos clientes. Nisto, percebe-se que o contador possui um papel importante de consultor dos diversos empreendedores que lhes confiam não apenas seus registros, mas a capacidade de gerar informações para a tomada de decisões, vitais em momentos como o vivenciado com esta pandemia.

Depreende-se a partir das análises, que ao contrário de outros setores, os escritórios contábeis não tiveram aumento nas demissões. Acredita-se que um dos fatos possa ser o aumento dos serviços ocasionados por outras demissões que precisaram ser realizadas pelos profissionais contábeis e pelo aumento dos estudos e repasse de informações aos clientes para adequação às leis e normas implementadas pelo Governo nesse período de pandemia.

Por fim, o estudo demonstrou que a maioria dos entrevistados não estão organizados, confortáveis, motivados para o trabalho em home office, uma vez que este tipo de trabalho afeta no desempenho das tarefas e a grande maioria dos entrevistados preferem a modalidade presencial.

Espera-se que outros trabalhos venham confrontar ou corroborar este estudo, uma vez que se trata de um exame realizado nos primeiros meses da pandemia no Brasil.

\section{REFERÊNCIAS BIBLIOGRÁFICAS}

CORREA, Luiz. O papel do Contador com o Coronavírus. 2020. Disponível em: <https://luizcorreacontador.com.br/o-papel-do-contador-com-o-coronavirus/ >. Acesso em: 27. Jun. 2020.

G1. Mundo registra mais de 6 milhões de casos de Covid-19, aponta universidade. 2020. Disponivel em:

$<$ https://g1.globo.com/bemestar/coronavirus/noticia/2020/05/31/mundo-registramais-de-6-milhoes-de-casos-de-covid-19-aponta-universidade.ghtml>. Acesso em:

31.mai.2020.

GANDRA, Alana. Indicador aponta impactos da covid-19 na economia brasileira. 2020. Disponível em: <https://agenciabrasil.ebc.com.br/economia/noticia/202005/indicador-aponta-impactos-da-covid-19-na-economia-brasileira >. Acesso em: 06. Jun. 2020.

GIL, A.C. Métodos e técnicas de pesquisa social. São Paulo: Atlas, 1999. 
HENDRIKSEN, Eldon S.; BREDA, Michael F. Van. Teoria da Contabilidade. 5.ed. São Paulo: Atlas, 1999.

IUDÍCIBUS, S. (Coord.). Contabilidade introdutória. 11.ed. São Paulo: Atlas, 2010

JUNIOR, R. R. F; RITA. L. P. S. Impactos da Covid-19 na Economia: limites, desafios e políticas. 2020. Disponível em: <https://cienciasmedicasbiologicas.ufba.br/index.php/nit/article/view/36183/20968>. Acesso em: 06. Jun. 2020.

MARQUES, Mano. 7 dicas para o contador ajudar o cliente. 2020. Disponível em: $<$ https://blog.fortestecnologia.com.br/dicas-para-contador-ajudar-o-cliente/>. Acesso em: 27. Jun. 2020.

OPAS - Organização Pan-Americana da Saúde. Folha informativa - COVID-19 (doença causada pelo novo coronavírus). 2020. Disponivel em: $<$ https://www.paho.org/bra/index.php?option=com_content $\& v i e w=\operatorname{article} \& i d=6101: \mathrm{co}$ vid19\&Itemid=875> . Acesso em: 31.mai.2020.

ROUBINI, Nouriel. A Greater Depression?. Project Syndicate, [S.1.], p. 1-5, 24 mar. 2020. Disponível em: <https://www.project-syndicate.org/commentary/coronavirusgreater-great-depression-by-nouriel-roubini-2020-03>. Acesso em: 06. Jun. 2020.

SANTOS, J. L. et al.. A importância do capital intelectual na sociedade do conhecimento. ConTexto, Porto Alegre, v. 8, n. 14, p. 1-16, 2º semestre 2008.

THOMÉ, I. Empresas de serviços contábeis: estrutura e funcionamento. São Paulo: Atlas, 2001.

VIELle, A. P. L.; BIANCHI, M. Profissão Contábil em Guias de Cursos de Graduação: Perfil Do Contador, Rotinas Profissionais e Mercado de Trabalho. 2016. Disponível em: $<$ http://local.cnecsan.edu.br/revista/index.php/rac/article/view/379 $>$. Acesso em: 27.mai.2020.

WRUBEL. F.; TOIGO. L.A.; LAVARDA. C.E.F.Mudanças Nas Rotinas Contábeis: Contradições Institucionais E Práxis Humanas. 2015. Disponível em: $<$ https://www.researchgate.net/publication/283563108_MUDANCAS_NAS_ROTI NAS_CONTABEIS_CONTRADICOES_INSTITUCIONAIS_E_PRAXIS_HUMANA $\underline{\text { S}}>$. Acesso em: 27.mai.2020. 